\title{
An Inventive Approach to Optimize Fuzzy Transportation Problem
}

\author{
Nirbhay Mathur \\ Department of Mathematics, \\ Shambhunath Institute of Engineering and Technology, Prayagraj, India. \\ E-mail: nirbhay12@rediffmail.com \\ Pankaj Kumar Srivastava \\ Department of Mathematics, \\ Jaypee Institute of Information Technology, Noida, India. \\ Corresponding author: pankaj.srivastava@jiit.ac.in
}

(Received February 3, 2020; Accepted April 2, 2020)

\begin{abstract}
The present paper wraps an innovative approach to optimize transportation problems through generalized trapezoidal numbers in a fuzzy environment. The main contribution here is to develop an innovative method to optimize the generalized fuzzy trapezoidal transportation problem and reduce the computational intricacy of the existing methods. Then again this method confers many improved results against classical North-West Corner and Least-Cost schemes in Fuzzy environment. An additional merit of the proposed scheme is that for several fuzzy transportation problems it furnishes the best possible way out directly. It is simple to understand and apply. The solution process is exemplified through two numerical examples and comparison with some standard existing methods.
\end{abstract}

Keywords- Fuzzy transportation problems, Generalized trapezoidal fuzzy numbers, Ranking function, Fuzzy minimum of demand supply, Modified distribution.

\section{Introduction}

The challenge now a day has become how to get maximum output by minimum input. One of the most significant and effective tools of quantitative study to solve big business problems of the various organizations has been in the circulation of items referred to as transportation problems. In essence, the objective is to play down the cost of transportation within the prescribed time domain. The largest part of the literature is based on crisp transport problems, but in real circumstances the ambiguity in data requires the use of generalized fuzzy number and this is the main motivation behind this study. At the beginning of 1930, Tolstoi proposed a piece of writing on cargo-shipping (Schrijver, 2002). In this, he discussed the transportation based problem and expressed a variety of solution thoughts. The first-ever imperative contribution to the formulation along with the computational practice of the basic problem of transportation was made by Hitchcock (1941). Such a problem has been represented as standard LPP and solved by the simplex methodology. The modified distribution and stepping stone optimal testing methods (Samuel and Venkatachalapathy, 2013; Mathur et al., 2016, Mathur et al., 2018) express a dissimilar way to find out the approach of the simplex method. These tests followed the procedure to get initial basic feasible solution (IBFS) via Vogel approximation method (VAM), the North-west corner (N-W-C) rule or least-cost (L-C) techniques to test the optimality of results. On occasions, it is not possible to get particular data for finding cost of transportation and therefore indistinct data can't be signified by indiscriminate random variables, in such situations records can be characterized regarded as fuzzy numbers (FNs) under fuzzy logic (Zadeh, 1965; Bisht and Srivastava, 2017; Bisht et al., 2018; Srivastava and Bisht, 2018; Srivastava et al., 2018; Barma et al, 2019; Srivastava and Bisht, 2019; Bisht and Srivastava, 
International Journal of Mathematical, Engineering and Management Sciences

Vol. 5, No. 5, 985-994, 2020

https://doi.org/10.33889/IJMEMS.2020.5.5.075

2020). This leads to the requirement of algorithms applicable in such indistinct data-based problems.

A variety of transport problems are tackled within Zimmermann's fuzzy linear programming (Zimmermann, 1978). Later on, the model on fuzzy programming to unravel transport problems has been developed (Chanas et al., 1984; Chanas and Kuchta, 1996). With the passage of time, plenty of algorithms have been built to solve the fuzzy transportation problem (FTP). The important of these are the extension principle model to explain and solve FTPs (Liu and Kao, 2004), use of demands/supplies in the form of trapezoidal fuzzy numbers (TrFNs) (Gani and Razak, 2006), application of TrFNs for the examination of FTP (Dinagar and Palanivel, 2009) and description of new methods for solving FTP by imaging the ambiguity of the outlay of transportation along with order and delivery of the item (Kaur and Kumar, 2011; Kaur and Kumar, 2012).

In the present article, an innovative approach is defined to solve generalized trapezoidal FTPs. In the projected method, generalized TrFNs are brought into play to represent the transportation cost of the product and minimum of the demand supply algorithm is applied to find the initial basic feasible solution of the defuzzified transportation problem through classical ranking technique. The algorithm proposed here is easily applicable by the decision-makers in real-life problems of transportation.

The present document is put up as follows: the objective of generalized FNs is presented in Section 2, while Section 3 covers some fundamental definitions, arithmetic operations with ranking functions. Section 4 contains a description of the new algorithm. In Section 5, the new idea has been tested through two examples and the comparative work is done in Section 6. The final section 7 is focused on concluding remarks.

\section{Objective of Generalized Fuzzy Number}

To take a worthy judgment decision-maker must compare FNs before taking a decision. So comparison plays a pivotal role in the problems based on decision making. Proposal of the concept for comparison of normal FNs (Jain, 1976) and that of the perception of generalized FNs, where there is no restriction of membership function as a normal form (Chen, 1985) were two significant works in the field. Since then, so many efforts are made for comparison of generalized FNs. Application of generalized FNs in real-life problems has been discussed by various researchers (Kumar and Amarpreet, 2011; Samuel and Venkatachalapathy, 2013; Ebrahimnejad, 2014).

Normalization is also an important tool to compare the FNs. Process of normalization is adopted by many authors, but that results of normalization process consequences in the loss of data information which is obtainable in original data was remarkable (Kaufmann and Gupta, 1991). Later on, the reduction of the length and complexity of arithmetical operations was also vital (Hsieh, 1999).

\section{Generalized Fuzzy Numbers}

In The elementary concepts of fuzzy set, TrFN, generalized FN with several primary operations and classical ranking technique can be described as (Bisht and Srivastava, 2019a; Bisht and Srivastava, 2019b; Chhibber et al., 2019; Mathur and Srivastava, 2019; Nagar et al., 2019): 
3.1 Definition: Consider a set $A$ such that $\mu_{A}(x)$ be a function from $A$ to $[0,1]$. Then set $A *$ is called fuzzy, having membership function $\mu_{\mathrm{A}}(\mathrm{x})$ such that

$A^{*}=\left\{\left(x, \mu_{A}(x): x \in A\right.\right.$ and $\left.\left.\mu_{A}(x) \in[0,1]\right)\right\}$.

3.2 Definition: Any fuzzy number $\mathrm{A}^{*}=\left(e_{1}, e_{2}, e_{3}, e_{4}\right)$ is called a $\operatorname{TrFN}$ if its membership function has the appearance:

$$
\mu_{\mathrm{A}^{*}}(x)=\left\{\begin{array}{cc}
\frac{x-e_{1}}{e_{2}-e_{1}}, & e_{1} \leq x \leq e_{2}, \\
\frac{1,}{x-e_{4}}, & e_{2} \leq x \leq e_{3}, \\
\frac{e_{3}-e_{4}}{0,} & e_{3} \leq x \leq e_{4}, \\
0 \text { otherwise. }
\end{array}\right.
$$

3.3 Definition: Any fuzzy number $\mathrm{A}^{*}=\left(e_{1}, e_{2}, e_{3}, e_{4}: w\right)$ is termed as generalized TrFN if its membership function has the appearance:

$$
\mu_{\mathrm{A}^{*}}(x)=\left\{\begin{array}{c}
w \frac{x-e_{1}}{e_{2}-e_{1}}, \quad e_{1} \leq x \leq e_{2}, \\
w, \quad e_{2} \leq x \leq e_{3}, \\
w \frac{x-e_{4}}{e_{3}-e_{4}}, \quad e_{3} \leq x \leq e_{4}, \\
0, \text { otherwise }
\end{array}\right.
$$

where $0 \leq w \leq 1$.

\subsection{Arithmetic Operations}

Let $\mathrm{A}=\left(e_{1}, e_{2}, e_{3}, e_{4}: w_{1}\right)$ and $\mathrm{B}=\left(f_{1}, f_{2}, f_{3}, f_{4}: w_{2}\right)$ are two generalized $\operatorname{TrFN}$, then:

(a) Addition $A+B=\left(e_{1}+f_{1}, e_{2}+f_{2}, e_{3}+f_{3}, e_{4}+f_{4} ; \min \left(w_{1}, w_{2}\right)\right)$,

(b) Multiplication $A \times B=\left(m_{1}, m_{2}, m_{3}, m_{4} ; \min \left(w_{1}, w_{2}\right)\right)$,

where $m_{1}=\min \left\{e_{1} f_{1}, e_{1} f_{4}, e_{4} f_{1}, e_{4} f_{4}\right\}$

$$
\begin{aligned}
& m_{2}=\min \left\{e_{2} f_{2}, e_{2} f_{3}, e_{3} f_{2}, e_{3} f_{3}\right\} \\
& m_{3}=\max \left\{e_{2} f_{2}, e_{2} f_{3}, e_{3} f_{2}, e_{3} f_{3}\right\} \\
& m_{4}=\max \left\{e_{1} f_{1}, e_{1} f_{4}, e_{4} f_{1}, e_{4} f_{4}\right\}, \\
& \text { (c) } l A= \begin{cases}\left(l e_{1}, l e_{2}, l e_{3}, l e_{4}\right) \text { for } l>0, \\
\left(l e_{4}, l e_{3}, l e_{3}, l e_{1}\right) \text { for } l<0 .\end{cases}
\end{aligned}
$$


International Journal of Mathematical, Engineering and Management Sciences

Vol. 5, No. 5, 985-994, 2020

https://doi.org/10.33889/IJMEMS.2020.5.5.075

\subsection{Classical Ranking Method}

The classical ranking function has been applied to convert a generalized $\operatorname{TrFN}$ into a crisp number and also hence used it to compare generalized TrFN.

Let $\mathrm{A}=\left(e_{1}, e_{2}, e_{3}, e_{4}: w_{1}\right)$ and $\mathrm{B}=\left(f_{1}, f_{2}, f_{3}, f_{4}: w_{2}\right)$ are two generalized TrFNs, then $R(A)=\frac{e_{1}+e_{2}+e_{3}+e_{4}}{4}$ and $R(B)=\frac{f_{1}+f_{2}+f_{3}+f_{4}}{4}$, where $w=\min \left(w_{1}, w_{2}\right)$.

Now we have the following three possible cases:

Case1. $R(A)>R(B)$ iff $A>\mathrm{B}$,

Case2. $R(A)<R(B)$ iff $A<\mathrm{B}$,

Case3. $R(A)=R(B)$ iff $A=\mathrm{B}$.

\section{Methodology}

In the optimization of transport, problems are solved by means of the supposition that the transportation cost, availability, as well as demand, are mentioned in a specific way. But in certain cases, it is not possible to find crisp details of the elements which are members of the transportation problem. In such instances, the related measures of the problem may write together by means of fuzzy sets, which results in the FTP (Kumar and Amarpreet, 2011; Kumar and Ram, 2018).

In this section, an inventive method is incorporated to find the initial basic feasible solution (IBFS). The proposed procedure (algorithm) involves subsequent steps for solving the transport problem:

Step I. Initially convert the given problem of transportation to a fuzzy LPP.

Step II. Set up the given problem into the fuzzy transportation matrix according to the objective to find the smallest transport cost.

Step III. Observe, if $\sum_{i=1}^{m} s_{i}=\sum_{j=1}^{n} d_{j}$ or if $\sum_{i=1}^{m} s_{i} \neq \sum_{j=1}^{n} d_{j}$.

Case (i) If $\sum_{i=1}^{m} s_{i}=\sum_{j=1}^{n} d_{j}$, go through level IV.

Case (ii) If $\sum_{i=1}^{m} s_{i}>\sum_{j=1}^{n} d_{j}$, place a zero dummy column so that $\sum_{i=1}^{m} s_{i}=\sum_{j=1}^{n} d_{j}$ as and go through the next level IV.

Case (iii) If $\sum_{i=1}^{m} s_{i}<\sum_{j=1}^{n} d_{j}$, place a zero dummy row so that $\sum_{i=1}^{m} s_{i}=\sum_{j=1}^{n} d_{j}$ as and go through the next level IV. 
International Journal of Mathematical, Engineering and Management Sciences

Vol. 5, No. 5, 985-994, 2020

https://doi.org/10.33889/IJMEMS.2020.5.5.075

Step IV. Opt for the least amount out of delivery and order i.e. $\min \left(s_{i}, d_{j}\right)$ and observe the matching row or column and locate the least cost $c_{i j}$ in observed row or column. Determine $x_{i j}=\min \left(s_{i}, d_{j}\right)$.

Case (i) If $\min \left(s_{i}, d_{j}\right)=s_{i}$ then allot $x_{i j}=s_{i}$ in $(i, j)$ cell of particular fuzzy transport matrix of order $m \times n$ and remove the matching $i^{\text {th }}$ row to obtain new fuzzy transport matrix of order $(m-1) \times n$. Replace $d_{j}$ by $d_{j}-s_{i}$ in new fuzzy transportation matrix.

Case (ii) If $\min \left(s_{i}, d_{j}\right)=d_{j}$ then allot $x_{i j}=d_{j}$ in $(i, j)$ cell of particular fuzzy transport matrix of order $m \times n$ and remove the matching $j^{\text {th }}$ column to obtain new fuzzy transport matrix of order $m \times(n-1)$. Replace $s_{i}$ by $s_{i}-d_{j}$ in new fuzzy transportation matrix.

Case (iii) If it's a tie in least amount of cost i.e. $c_{i j}$ opt that $(i, j)$ cell in which $\min \left(s_{i}, d_{j}\right)$ and go through the next level V.

Case (iv) If $s_{i}=d_{j}$ opt that $(i, j)$ element in which cost $c_{i j}$ is least in consequent row or column and go back to level IV.

Step V. Continue repetition of above step IV until the fuzzy transportation matrix in consideration shrink to the matrix of order $1 \times 1$.

Step VI. Allot all $x_{i j}$ in the matching $(i, j)$ element of the original fuzzy transport matrix.

Step VII. The IBFS and preliminary cost of fuzzy transportation are $x_{i j}$ and $\sum_{i=1}^{m} \sum_{j=1}^{n} c_{i j} x_{i j}$.

\section{Numerical Examples}

This section puts forward two illustrations to demonstrate the utility of the projected approach. The illustrations are reviewed against some standard methods (Kaur and Kumar, 2012; Samuel and Venkatachalapathy, 2013). The recommended algorithm requires less computational time.

Example 1: Consider the problem form (Kaur and Kumar, 2012) represented in Table 1.

Table 1. Availability and demand detail

\begin{tabular}{|l|c|c|c|c|}
\hline & $\mathrm{K}_{1}$ & $\mathrm{~K}_{2}$ & $\mathrm{~K}_{3}$ & Available item $\left(\mathrm{s}_{\mathrm{i}}\right)$ \\
\hline $\mathrm{L}_{1}$ & $(1,4,9,19 ; .5)$ & $(1,2,5,9 ; .4)$ & $(2,5,8,18 ; .5)$ & 10 \\
\hline $\mathrm{L}_{2}$ & $(8,9,12,26 ; .5)$ & $(3,5,8,12 ; .2)$ & $(7,9,13,28 ; .4)$ & 14 \\
\hline $\mathrm{L}_{3}$ & $(11,12,20,27 ; .5)$ & $(0,5,10,15 ; .8)$ & $(4,5,8,11 ; .6)$ & 15 \\
\hline requirement $\left(\mathrm{d}_{\mathrm{j}}\right)$ & 15 & 14 & 10 & \\
\hline
\end{tabular}


International Journal of Mathematical, Engineering and Management Sciences

Vol. 5, No. 5, 985-994, 2020

https://doi.org/10.33889/IJMEMS.2020.5.5.075

Solution: In this section, the minimum demand supply method is applied to obtain the initial cost of fuzzy transportation and IBFS. The minimum supply / demand of Table 1 are 10 for availability $\mathrm{L}_{1}$ and demand $\mathrm{K}_{3}$. So there is a tie in demand and supply. So, choose the cost which is minimum (checked through ranking) for corresponding demand and supply, which is corresponding to $\mathrm{L}_{1}$ and $\mathrm{K}_{2}$. The allocation at this stage is minimum of $\{10,14\}=10$. Allocate $\mathrm{X}_{12}=10$ at cell corresponding to $L_{1}$ and $K_{2}$ of Table 1 , the balance demand at $K_{2}$ is $14-10=4$.

Table 2. First iteration

\begin{tabular}{|l|c|c|c|c|}
\hline & $\mathrm{K}_{1}$ & $\mathrm{~K}_{2}$ & $\mathrm{~K}_{3}$ & Available item $\left(\mathrm{s}_{\mathrm{i}}\right)$ \\
\hline $\mathrm{L}_{1}$ & $(1,4,9,19 ; .5)$ & $(1,2,5,9 ; .4)$ & $(2,5,8,18 ; .5)$ & 10 \\
\hline $\mathrm{L}_{2}$ & $(8,9,12,26 ; .5)$ & $(3,5,8,12 ; .2)$ & $(7,9,13,28 ; .4)$ & 14 \\
\hline $\mathrm{L}_{3}$ & $(11,12,20,27 ; .5)$ & $(0,5,10,15 ; .8)$ & $(4,5,8,11 ; .6)$ & 15 \\
\hline requirement $\left(\mathrm{d}_{\mathrm{j}}\right)$ & 15 & 144 & 10 & \\
\hline
\end{tabular}

Because of zero availability at $S_{1}$, the first row is ignored and so Table 2 converts to a table of order $2 \times 3$ given in Table 3 .

Table 3. Second iteration

\begin{tabular}{|l|c|c|c|c|}
\hline & $\mathrm{K}_{1}$ & $\mathrm{~K}_{2}$ & $\mathrm{~K}_{3}$ & Available item $\left(\mathrm{s}_{\mathrm{i}}\right)$ \\
\hline $\mathrm{L}_{2}$ & $(8,9,12,26 ; .5)$ & $(3,5,8,12 ; .2)$ & $(7,9,13,28 ; .4)$ & 14 \\
\hline $\mathrm{L}_{3}$ & $(11,12,20,27 ; .5)$ & $(0,5,10,15 ; .8)$ & $(4,5,8,11 ; .6)$ & 15 \\
\hline requirement $\left(\mathrm{d}_{\mathrm{j}}\right)$ & 15 & 4 & 10 & \\
\hline
\end{tabular}

Repeating the procedure until we get the table of order $1 \times 1$ such that the IBFS will be $A_{12}=10, A_{21}=10, A_{22}=4, A_{31}=5, A_{33}=10$.

The initial cost of fuzzy transport $=(197,240,382,643: 0.2)$.

The obtained IBFS is revealed in Table 4.

Table 4. Initial basic feasible solution (IBFS)

\begin{tabular}{|l|c|c|c|c|}
\hline & $\mathrm{K}_{1}$ & $\mathrm{~K}_{2}$ & $\mathrm{~K}_{3}$ & Available item $\left(\mathrm{s}_{\mathrm{i}}\right)$ \\
\hline $\mathrm{L}_{1}$ & $(1,4,9,19 ; .5)$ & $(1,2,5,9 ; .4)$ & $(2,5,8,18 ; .5)$ & 10 \\
\hline $\mathrm{L}_{2}$ & $(8,9,12,26 ; .5)$ & $\mathbf{1 0}$ & $(7,5,8,12 ; .2)$ & 14 \\
\hline $\mathrm{L}_{3}$ & $(11,12,20,27 ; .5)$ & $\mathbf{4}$ & $(4,9,13,28 ; .4)$ & 15 \\
\hline requirement $\left(\mathrm{d}_{\mathrm{j}}\right)$ & $\mathbf{5}$ & $(0,5,10,15 ; .8)$ & $\mathbf{1 0}$ & 10 \\
\hline
\end{tabular}

And the best result using GFMDM (Generalized fuzzy modified distribution method) $=(117,205,352,613: 0.2)$. 
International Journal of Mathematical, Engineering and Management Sciences

Vol. 5, No. 5, 985-994, 2020

https://doi.org/10.33889/IJMEMS.2020.5.5.075

Example 2: Consider the following generalized FTP which is represented in Table 5 (Samuel and Venkatachalapathy, 2013). All of the data in this problem are generalized trapezoidal fuzzy numbers except demand and supply. Obtain optimal cost of transporting products in such a way the complete cost of fuzzy transport remains lowest.

Table 5. Availability and demand detail

\begin{tabular}{|c|c|c|c|c|c|}
\hline & $\mathrm{K}_{1}$ & $\mathrm{~K}_{2}$ & $\mathrm{~K}_{3}$ & $\mathrm{~K}_{4}$ & Available items ( $\left.\mathrm{s}_{\mathrm{i}}\right)$ \\
\hline $\mathrm{L}_{1}$ & $(1,4,8,11 ; 0.6)$ & $(0,1,2,3 ; 0.4)$ & $(3,7,10,16 ; 0.5)$ & $(1,2,4,5 ; 0.5)$ & 70 \\
\hline $\mathrm{L}_{2}$ & $(4,10,12,18 ; 0.3)$ & $(1,3,6,10 ; 0.2)$ & $(0,1,3,4 ; 0.5)$ & $(3,5,9,15 ; 0.2)$ & 55 \\
\hline $\mathrm{L}_{3}$ & $(4,9,12,15 ; 0.2)$ & $(6,10,14,18 ; 0.6)$ & $(2,3,5,6 ; 0.2)$ & $(4,6,8,10 ; 0.2)$ & 90 \\
\hline Requirement $\left(\mathrm{d}_{\mathrm{j}}\right)$ & 85 & 35 & 50 & 45 & \\
\hline
\end{tabular}

Solution: Using the proposed algorithm, the obtained IBFS for the above problem is $A_{12}=35, A_{14}=35, A_{21}=5, A_{23}=50, A_{31}=80, A_{34}=10$.

The obtained IBFS is shown in Table 6.

Table 6. Initial Basic Feasible Solution

\begin{tabular}{|c|c|c|c|c|c|}
\hline & $\mathrm{K}_{1}$ & $\mathrm{~K}_{2}$ & $\mathrm{~K}_{3}$ & $\mathrm{~K}_{4}$ & Available items $\left(\mathrm{s}_{\mathrm{i}}\right)$ \\
\hline $\mathrm{L}_{1}$ & $(1,4,8,11 ; .6)$ & $(0,1,2,3 ; .4)$ & $(3,7,10,16 ; .5)$ & $\begin{array}{c}(1,2,4,5 ; .5) \\
35\end{array}$ & 70 \\
\hline $\mathrm{L}_{2}$ & $\begin{array}{c}(4,10,12,18 ; .3) \\
\mathbf{5}\end{array}$ & $(1,3,6,10 ; .2)$ & $\begin{array}{c}(0,1,3,4 ; .5) \\
\mathbf{5 0}\end{array}$ & $\begin{array}{c}(3,5,9,15 ; .2) \\
5\end{array}$ \\
\hline $\mathrm{L}_{3}$ & $\begin{array}{c}(4,9,12,15 ; .2) \\
\mathbf{8 0}\end{array}$ & $(6,10,14,18 ; .6)$ & $(2,3,5,6 ; .2)$ & $\begin{array}{c}(4,6,8,10 ; .2) \\
\mathbf{1 0}\end{array}$ & 90 \\
\hline Requirement $\left(\mathrm{d}_{\mathrm{j}}\right)$ & 85 & 35 & 50 & 45 & \\
\hline
\end{tabular}

The initial fuzzy transportation cost $=(415,985,1460,1870: 0.2)$, and the optimal solution using GFMDM $=(415,970,1460,1865: 0.2)$.

\section{Comparative Study}

\subsection{Comparison Based on Allocation}

To demonstrate the usefulness of the proposed scheme a healthy comparison has been exposed from Table 7 to 10 . This comparison covers allocation by the proposed scheme and that made by some other standard methods (Kaur and Kumar, 2012; Samuel and Venkatachalapathy, 2013) respectively of Example 1 and 2 represented in Table 7 and 8.

Table 7. Comparison for allocation (Example 1)

\begin{tabular}{|c|c|c|c|c|c|c|}
\hline & \multicolumn{2}{|c|}{$\mathrm{K}_{1}$} & \multicolumn{2}{|c|}{$\mathrm{K}_{2}$} & \multicolumn{2}{|c|}{$\mathrm{K}_{3}$} \\
\hline & $\begin{array}{c}\text { Kaur and } \\
\text { Kumar (2012) }\end{array}$ & $\begin{array}{l}\text { Proposed } \\
\text { approach }\end{array}$ & $\begin{array}{c}\text { Kaur and } \\
\text { Kumar (2012) }\end{array}$ & $\begin{array}{l}\text { Proposed } \\
\text { approach }\end{array}$ & $\begin{array}{c}\text { Kaur and } \\
\text { Kumar (2012) }\end{array}$ & $\begin{array}{l}\text { Proposed } \\
\text { approach }\end{array}$ \\
\hline $\mathrm{L}_{1}$ & $\checkmark$ & $x$ & $x$ & $\checkmark$ & $x$ & $x$ \\
\hline $\mathrm{L}_{2}$ & $\checkmark$ & $\checkmark$ & $\checkmark$ & $\checkmark$ & $x$ & $x$ \\
\hline $\mathrm{L}_{3}$ & $x$ & $\checkmark$ & $\checkmark$ & $x$ & $\checkmark$ & $\checkmark$ \\
\hline
\end{tabular}


International Journal of Mathematical, Engineering and Management Sciences

Vol. 5, No. 5, 985-994, 2020

https://doi.org/10.33889/IJMEMS.2020.5.5.075

Table 8. Comparison for allocation (Example 2)

\begin{tabular}{|c|c|c|c|c|c|c|c|c|}
\hline & \multicolumn{2}{|c|}{$\mathrm{K}_{1}$} & \multicolumn{2}{c|}{$\mathrm{K}_{2}$} & \multicolumn{2}{c|}{$\mathrm{K}_{3}$} & \multicolumn{2}{c|}{$\mathrm{K}_{4}$} \\
\hline & $\begin{array}{c}\text { Samuel and } \\
\text { Venkatachalapathy } \\
(2013)\end{array}$ & $\begin{array}{c}\text { Proposed } \\
\text { approach }\end{array}$ & $\begin{array}{c}\text { Samuel and } \\
\text { Venkatachalapathy } \\
(2013)\end{array}$ & $\begin{array}{c}\text { Proposed } \\
\text { approach }\end{array}$ & $\begin{array}{c}\text { Samuel and } \\
\text { Venkatachalapathy } \\
(2013)\end{array}$ & $\begin{array}{c}\text { Proposed } \\
\text { approach }\end{array}$ & $\begin{array}{c}\text { Samuel and } \\
\text { Venkatachalapathy } \\
(2013)\end{array}$ & $\begin{array}{c}\text { Proposed } \\
\text { approach }\end{array}$ \\
\hline $\mathrm{L}_{1}$ & $\boldsymbol{V}$ & $\boldsymbol{x}$ & $\boldsymbol{V}$ & $\boldsymbol{V}$ & $\boldsymbol{x}$ & $\boldsymbol{x}$ & $\boldsymbol{V}$ & $\boldsymbol{V}$ \\
\hline $\mathrm{L}_{2}$ & $\boldsymbol{V}$ & $\boldsymbol{V}$ & $\boldsymbol{x}$ & $\boldsymbol{x}$ & $\boldsymbol{V}$ & $\boldsymbol{V}$ & $\boldsymbol{x}$ & $\boldsymbol{x}$ \\
\hline $\mathrm{L}_{3}$ & $\boldsymbol{x}$ & $\boldsymbol{V}$ & $\boldsymbol{x}$ & $\boldsymbol{x}$ & $\boldsymbol{V}$ & $\boldsymbol{x}$ & $\boldsymbol{V}$ & $\boldsymbol{V}$ \\
\hline
\end{tabular}

\subsection{Comparison Based on Optimal Solution and Epochs}

In addition, optimal solution and epochs involved getting optimal solution of Example 1 and Example 2 by generalized fuzzy N-W-C method, generalized fuzzy L-C method, generalized fuzzy Vogel approximation method (VAM), generalized fuzzy MODI and proposed generalized fuzzy min demand supply approach has been established in Table 9 and 10.

Table 9. Comparison based on optimal solution and epochs (Example 1)

\begin{tabular}{|l|c|c|c|c|c|}
\hline \multirow{2}{*}{ Example 1 } & \multicolumn{4}{|c|}{ Earlier Methods } & Proposed Method \\
\cline { 2 - 6 } & $\begin{array}{c}\text { GFNWCM (Generalized } \\
\text { Fuzzy N-W-C Method) }\end{array}$ & $\begin{array}{c}\text { GFLCM (Generalized } \\
\text { Fuzzy L-C Method) }\end{array}$ & $\begin{array}{c}\text { GFVAM } \\
\text { (Generalized Fuzzy } \\
\text { VAM) }\end{array}$ & $\begin{array}{c}\text { GFMDM } \\
\text { (Generalized Fuzzy } \\
\text { MODI) }\end{array}$ & $\begin{array}{c}\text { Generalized Fuzzy Min } \\
\text { Demand Supply } \\
\text { Approach }\end{array}$ \\
\hline Solution & $(117,205,352,613 ; .2)$ & $(197,240,382,643 ; .2)$ & $(147,220,382,603 ; .2)$ & $(117,205,352,613 ; 2)$ & $(197,240,382,643 ; .2)$ \\
\hline Epochs & 1 & 4 & 2 & Optimum & 4 \\
\hline
\end{tabular}

Table 10. Comparison based on optimal solution and epochs (Example 2)

\begin{tabular}{|l|c|c|c|c|c|}
\hline \multirow{3}{*}{ Example 2 } & \multicolumn{4}{|c|}{ Earlier Methods } & Proposed Method \\
\cline { 2 - 6 } & $\begin{array}{c}\text { GFNWCM } \\
\text { (Generalized Fuzzy N- } \\
\text { W-C Method) }\end{array}$ & $\begin{array}{c}\text { GFLCM (Generalized } \\
\text { Fuzzy L-C Method) }\end{array}$ & $\begin{array}{c}\text { GFVAM (Generalized } \\
\text { Fuzzy VAM) }\end{array}$ & $\begin{array}{c}\text { GFMDM (Generalized } \\
\text { Fuzzy MODI) }\end{array}$ & $\begin{array}{c}\text { Generalized Fuzzy } \\
\text { Min Demand } \\
\text { Supply Approach }\end{array}$ \\
\hline Solution & $(435,945,1550,2130 ;$ & $(415,985,1460,1870 ;$ & $(405,900,1520,2055 ;$ & $(405,970,1460,1865 ;$ & $(415,985,1460$, \\
& $.2)$ & $.2)$ & $.2)$ & $2)$ & $1870 ; .2)$ \\
\hline Epochs & 3 & 2 & 2 & Optimum & 2 \\
\hline
\end{tabular}

There are several methods to solve generalized FTPs to obtain an IBFS but this method requires less calculation with respect to other methods. It is discussed in (Kaur and Kumar, 2012) that we cannot say which method gives optimal or near to optimal result in a few problems but in these cases, this method gives optimal solution.

\section{Conclusion}

In the present manuscript, a more efficient algorithm via generalized TrFNs is conferred to optimize transportation problem. In the proposed algorithm, the cost of transporting the items are represented by FNs based on the generalized trapezoidal system. The new algorithm consumes less time and it is an organized procedure. In view of the fact that the proposed process is faster in terms of calculation, it will be extremely supportive for assessment makers who are in the contract of logistic and supply chain. This study can be extended to FTPs constructed of higher generalized FNs. 
International Journal of Mathematical, Engineering and Management Sciences

Vol. 5, No. 5, 985-994, 2020

https://doi.org/10.33889/IJMEMS.2020.5.5.075

\section{Conflict of Interest}

Both authors have contributed equally to this work. The authors declare that there is no conflict of interest for this publication.

\section{Acknowledgement}

The authors extend their appreciation to the anonymous reviewers for their valuable suggestions.

\section{References}

Barma, P.S., Dutta, J., \& Mukherjee, A. (2019). A 2-opt guided discrete antlion optimization algorithm for multi-depot vehicle routing problem.Decision Making: Applications in Management and Engineering, 2(2), 112-125.

Bisht, D.C., \& Srivastava, P.K. (2019a). Fuzzy optimization and decision making. In: Ram, M. (ed) Advanced Fuzzy Logic Approaches in Engineering Science, IGI, Global Publisher, pp. 310-326.

Bisht, D.C.S., \& Srivastava, P.K. (2019b). One point conventional model to optimize trapezoidal fuzzy transportation problem. International Journal of Mathematical, Engineering and Management Sciences, $4(5), 1251-1263$.

Bisht, D.C.S., \& Srivastava, P.K. (2020). Trisectional fuzzy trapezoidal approach to optimize interval data based transportation problem. Journal of King Saud University-Science, 32(1), 195-199.

Bisht, D.C.S., Srivastava, P.K., \& Ram, M. (2018). Role of fuzzy logic in flexible manufacturing system. In: Ram, M., Davim, J.P. (eds) Diagnostic Techniques in Industrial Engineering. Springer, Cham, pp. 233243.

Bisht, D., \& Srivastava, P.K. (2017). A unique conversion approach clubbed with a new ranking technique to optimize fuzzy transportation cost. In AIP Conference Proceedings, 1897(1), 020023.

Chanas, S., Kolodziejczyk, W., \& Machaj, A. (1984). A fuzzy approach to the transportation problem. Fuzzy Sets and Systems, 13(3), 211-221.

Chanas, S., \& Kuchta, D. (1996). A concept of the optimal solution of the transportation problem with fuzzy cost coefficients. Fuzzy Sets and Systems, 82(3), 299-305.

Chen, S.H. (1985). Operations on fuzzy numbers with function principal. Journal of Management Science, 6(1), 13-26.

Chhibber, D., Bisht, D.C.S., \& Srivastava, P.K. (2019). Ranking approach based on incenter in triangle of centroids to solve type-1 and type-2 fuzzy transportation problem. AIP Conference Proceedings, 2061(1), 020022.

Dinagar, D.S., \& Palanivel, K. (2009). The transportation problem in fuzzy environment. International Journal of Algorithms, Computing and Mathematics, 2(3), 65-71.

Ebrahimnejad, A. (2014). A simplified new approach for solving fuzzy transportation problems with generalized trapezoidal fuzzy numbers. Applied Soft Computing, 19, 171-176.

Gani, A.N., \& Razak, K.A. (2006). Two stage fuzzy transportation problem. Journal of Physical Science, 10, 63-69.

Hitchcock, F.L. (1941). The distribution of a product from several sources to numerous localities. Journal of Mathematics and Physics, 20(1-4), 224-230.

Hsieh, C.H. (1999). Similarity of generalized fuzzy numbers with graded mean integration representation. In Proceeding of 8th International Fuzzy Systems Association World Congress, 2, 551-555. 
International Journal of Mathematical, Engineering and Management Sciences

Vol. 5, No. 5, 985-994, 2020

https://doi.org/10.33889/IJMEMS.2020.5.5.075

Jain, R. (1976). Decision making in the presence of fuzzy variables. IEEE Transaction on Systems, Man and Cybernetics, 6(10), 698-703.

Kaufman, A., \& Gupta, M.M. (1991). Introduction to fuzzy arithmetic. Van Nostrand Reinhold Company New York.

Kaur, A., \& Kumar, A. (2011). A new method for solving fuzzy transportation problems using ranking function. Applied Mathematical Modelling, 35(12), 5652-5661.

Kaur, A., \& Kumar, A. (2012). A new approach for solving fuzzy transportation problems using generalized trapezoidal fuzzy numbers. Applied Soft Computing, 12(3), 1201-1213.

Kumar, A., \& Amarpreet, K. (2011). Application of classical transportation methods for solving fuzzy transportation problems. Journal of Transportation Systems Engineering and Information Technology, $11(5), 68-80$.

Kumar, A., \& Ram, M. (2018). System reliability analysis based on weibull distribution and hesitant fuzzy set. International Journal of Mathematical, Engineering and Management Sciences, 3(4), 513-521.

Liu, S.-T., \& Kao, C. (2004). Solving fuzzy transportation problems based on extension principle. European Journal of Operational Research, 153(3), 661-674.

Mathur, N., \& Srivastava, P.K. (2019). A pioneer optimization approach for hexagonal fuzzy transportation problem. AIP Conference Proceedings, 2061(1), 020030.

Mathur, N., Srivastava, P.K., \& Paul, A. (2016). Trapezoidal fuzzy model to optimize transportation problem. International Journal of Modeling, Simulation, and Scientific Computing, 7(3), 1650028.

Mathur, N., Srivastava, P.K., \& Paul, A. (2018). Algorithms for solving fuzzy transportation problem. International Journal of Mathematics in Operational Research, 12(2), 190-219.

Nagar, P., Srivastava, A., \& Srivastava, P.K. (2019). Optimization of species transportation via an exclusive fuzzy trapezoidal centroid approach. Mathematics in Engineering, Science and Aerospace, 10(2), 271280.

Samuel, A.E., \& Venkatachalapathy, M. (2013). A simple heuristic for solving generalized fuzzy transportation problems. International Journal of Pure and Applied Mathematics, 83(1), 91-100.

Schrijver, A. (2002). On the history of the transportation and maximum flow problems. Mathematical Programming, 91(3), 437-445.

Srivastava, P.K., \& Bisht, D.C.S. (2018). Dichotomized incenter fuzzy triangular ranking approach to optimize interval data based transportation problem. Cybernetics and Information Technologies, 18(4), 111-119.

Srivastava, P.K., \& Bisht, D.C.S. (2019). Recent trends and applications of fuzzy logic. In: Ram, M. (ed) Advanced Fuzzy Logic Approaches in Engineering Science, IGI, Global Publisher, pp. 327-340.

Srivastava, P.K., Bisht, D., \& Ram, M. (2018). Soft computing techniques and applications. In: Ram, M., Davim, J.P. (eds) Advanced Mathematical Techniques in Engineering Sciences. CRC Press - Taylor \& Francis, Boca Raton, pp. 57-69.

Zadeh, L.A. (1965). Fuzzy sets. Information and control, 8(3), 338-353.

Zimmermann, H.J. (1978). Fuzzy programming and linear programming with several objective functions. Fuzzy Sets and Systems, 1(1), 45-55. 